\title{
Time-varying cointegration with an application to the UK Great Ratios
}

\author{
George Kapetanios \\ Stephen Millard \\ Katerina Petrova \\ King's College London \\ Bank of England and CFM \\ UPF and Barcelona GSE \\ Simon Price \\ Essex Business School, City University London and CAMA *
}

April 8, 2020

\begin{abstract}
We build on an estimation method which can accommodate time variation in a cointegrating relationship and present a test for cointegration under this setup. We apply our test procedure to the UK Great Ratios and find little evidence for cointegration when the parameters are assumed constant, but strong evidence when allowing them to drift slowly over time.
\end{abstract}

JEL Codes: C14, C26, C51, O4

Keywords: Time variation, Great Ratios, cointegration.

\section{HIGHLIGHTS}

- We build on an estimation method and test for cointegrating relationships in the presence of time variation.

- We apply this to the UK Great Ratios and find strong evidence for changing cointegrating relationships.

${ }^{*}$ The views expressed in this paper are those of the authors, and not necessarily those of the Bank of England or its committees. Declaration of interest: none. Corresponding author: Simon Price, EBS, University of Essex, Wivenhoe Park, Colchester CO4 3SQ UK, s.g.price@essex.ac.uk, +44 (0)1206873843. 


\section{Cointegration with time-varying parameters}

We extend the literature on time variation (TV) in the setup of cointegrating relationship $\xi^{1}$ by generalising the kernel estimators of Giraitis et al. (2018) to a cointegrating regression model, proving consistency, and proposing a cointegration test based on the residuals computed with time variation in the parameters.

Let $y_{t}$ and a $k \times 1$ vector $x_{t}$ be $I(1)$ processes. In the standard case $y_{t}$ and $x_{t}$ cointegrate if there exists a $k \times 1$ vector of constant parameters $\beta$ which delivers an $I(0)$ linear combination $u_{t}$ between $y_{t}$ and $x_{t}$ :

$$
u_{t}=y_{t}-x_{t}^{\prime} \beta \text {. }
$$

We generalise this definition to allow for a persistent and bounded time-varying vector $\beta_{t}$ which results in a cointegrating regression of the form

$$
y_{t}=x_{t}^{\prime} \beta_{t}+u_{t}
$$

We assume that $\beta_{t}$ satisfies

$$
\sup _{|s|<s_{0}}\left\|\beta_{t}-\beta_{t-s}\right\|=O_{p}\left(\left(\frac{s_{0}}{t}\right)^{\gamma}\right) \text { for some } 0<\gamma \leq 1 .
$$

Condition (3) implies that the sequence of parameters drifts slowly with time, a property that is sufficient for consistent estimation of $\beta_{t}$. This covers the constant case as well as deterministic piecewise differentiable processes assumed in the work of Dahlhaus on locally stationary processes (e.g. Dahlhaus 2000) or Dahlhaus and Polonik (2006)). Condition (3) also includes stochastic parameter processes exhibiting a degree of persistence necessary for consistent estimation of stochastically driven TV. These include bounded random walk processes, as well as some fractionally integrated processe: $2^{2}$. In a related paper, Park and Hahn (1999) assume the parameter is a deterministic function of time $f(t / T)$, which is covered by our condition (3), but instead use a series expansion to approximate the TV parameters.

Under the TV parameter framework of (3), an extremum estimator for $\beta_{t}$ is derived by minimising an objective function $\widehat{\beta}_{t}=\arg \min _{\beta} \sum_{j=1}^{T} k_{t j} u_{j}^{2}$ :

$$
\widehat{\beta}_{t}=\left(\sum_{j=1}^{T} k_{t j} x_{j} x_{j}^{\prime}\right)^{-1}\left(\sum_{j=1}^{T} k_{t j} x_{j} y_{j}\right)
$$

where the weights $k_{t j}$ are generated by a kernel, $k_{t j}:=K((t-j) / H)$, where $K(x) \geq 0, x \in \mathbb{R}$ is a bounded function and $H$ is a bandwidth parameter such that $H \rightarrow \infty, H=o(T / \log T)$. The kernel estimator $\widehat{\beta}_{t}$ is a simple generalisation of a rolling window estimator of the form

$$
\widehat{\beta}_{t}=\left(\sum_{j=t-H}^{t+H} x_{j} x_{j}^{\prime}\right)^{-1}\left(\sum_{j=t-H}^{t+H} x_{j} y_{j}\right) .
$$

\footnotetext{
${ }^{1}$ A seminal paper is Bierens and Martins (2010).

${ }^{2}$ In addition, parameters can be a linear combination of deterministic and stochastic processes themselves satisfying 3 .
} 
We assume that $K$ is a non-negative bounded function with a piecewise bounded derivative $\dot{K}(x)$ such that $\int K(x) d x=1$. Examples include

$$
\begin{aligned}
& K(x)=(1 / 2) I(|x| \leq 1), \quad \text { flat kernel, } \\
& K(x)=(3 / 4)\left(1-x^{2}\right) I(|x| \leq 1), \quad \text { Epanechnikov kernel, } \\
& K(x)=(1 / \sqrt{2 \pi}) e^{-x^{2} / 2}, \quad \text { Gaussian kernel. }
\end{aligned}
$$

If $K$ has unbounded support, we assume in addition that

$$
K(x) \leq C \exp \left(-c x^{2}\right), \quad|\dot{K}(x)| \leq C\left(1+x^{2}\right)^{-1}, \quad x \geq 0, \quad \text { for some } C>0, c>0 .
$$

When $x_{t}$ and $y_{t}$ are stationary and $\gamma=1 / 2$, Giraitis et al. (2018) show that assuming a martingale difference error process, the kernel estimator $\hat{\beta}_{t}$ is consistent: $\hat{\beta}_{t}-\beta_{t}=O_{p}\left(\left(\frac{1}{H}\right)^{1 / 2}\right)+O_{p}\left(\left(\frac{H}{T}\right)^{1 / 2}\right)$. Further, if $x_{t}$ is a unit root process and $\beta_{t}$ is deterministic, then Phillips et al. (2017) have shown consistency and derived rates for $\widehat{\beta}_{t}$.

In this paper, we wish to test the hypothesis that $u_{t}$ is an $I(0)$ process in the presence of parameter time variation, assuming that $\beta_{t}$ satisfies condition (3). We extend the cointegrating KPSS test (null of stationarity around a deterministic trend) 3 with a statistic based on the kernel estimate $\widehat{\beta}_{t}$. We define the model's residuals by

$$
\hat{u}_{t}=y_{t}-x_{t}^{\prime} \widehat{\beta}_{t}
$$

and the KPSS test statistic by

$$
C I=\frac{T^{-2} h \sum_{j=1}^{T} S_{j}^{2}}{\hat{s}^{2}}
$$

where $h=H / T, \hat{s}^{2}$ is an estimate of the long run variance of $\hat{u}_{t}$ and $S_{[T r]}=\sum_{j=1}^{[T r]} \hat{u}_{j}$. The asymptotic distribution of the test statistic $C I$ defined above follows once we note that

$$
T^{-2} h \sum_{j=1}^{T} S_{j}^{2}=T^{-1} \sum_{j=1}^{T}\left(T^{-1 / 2} h^{1 / 2} S_{j}\right)^{2} \Longrightarrow Q^{2}
$$

where $Q=\sqrt{2} \int_{-1}^{1} K(s) d B_{y,(s+1) / 2}^{*}$.

We next sketch a derivation of Equation (5), considering the proof of Theorem 1 of Shin (1994). First, note that

$$
T^{-1 / 2} S_{[T r]}=T^{-1 / 2} \sum_{j=1}^{[T r]} \hat{u}_{j}=T^{-1 / 2} \sum_{j=1}^{[T r]} u_{j}-T^{-3 / 2} \sum_{j=1}^{[T r]} x_{j} T(\hat{\beta}-\beta) .
$$

The time-varying version of this expression is

$$
T^{-1 / 2} h^{1 / 2} S_{[T r]}=T^{-1 / 2} h^{1 / 2} \sum_{j=1}^{[T r]} \hat{u}_{j}=T^{-1 / 2} h^{1 / 2} \sum_{j=1}^{[T r]} u_{j}-T^{-3 / 2} \sum_{j=1}^{[T r]} x_{j} T h^{1 / 2}\left(\hat{\beta}_{j}-\beta_{j}\right),
$$

\footnotetext{
${ }^{3} \mathrm{KPSS}$ is often preferred to alternative tests as under null hypotheses of non-stationarity, alternative tests can misbehave.
} 
where $T^{-1 / 2} h^{1 / 2} \sum_{j=1}^{[T r]} u_{j}=O_{p}\left(h^{1 / 2}\right)=o_{p}(1)$. We focus on the remaining term $T^{-3 / 2} \sum_{j=1}^{[T r]} x_{j} T h^{1 / 2}\left(\hat{\beta}_{j}-\beta_{j}\right)$. We have by Phillips et al. (2017) that for $j=[T r]$,

$$
T h^{1 / 2}\left(\hat{\beta}_{j}-\beta_{j}\right)=T h^{1 / 2}\left(\hat{\beta}_{[T r]}-\beta_{[T r]}\right) \Longrightarrow \Delta_{r}^{-1} \Gamma_{r}
$$

where

$$
\begin{aligned}
\Delta_{r} & =B_{x, r}^{2} \\
\Gamma_{r} & =\sqrt{2} B_{x, r} \int_{-1}^{1} K(s) d B_{y,(s+1) / 2}^{*} .
\end{aligned}
$$

Therefore,

$$
T h^{1 / 2}\left(\hat{\beta}_{j}-\beta_{j}\right)=T h^{1 / 2}\left(\hat{\beta}_{[T r]}-\beta_{[T r]}\right) \Longrightarrow \sqrt{2} B_{x, r}^{-1} \int_{-1}^{1} K(s) d B_{y,(s+1) / 2}^{*}
$$

and

$$
\begin{aligned}
T^{-3 / 2} \sum_{j=1}^{[T r]} x_{j} T h^{1 / 2}\left(\hat{\beta}_{j}-\beta_{j}\right) & =T^{-1} \sum_{j=1}^{[T r]} \frac{x_{j}}{T^{1 / 2}} T h^{1 / 2}\left(\hat{\beta}_{j}-\beta_{j}\right) \Longrightarrow \sqrt{2} \int_{0}^{1} B_{x, r}\left(B_{x, r}^{-1}\right)\left[\int_{-1}^{1} K(s) d B_{y,(s+1) / 2}^{*}\right] d r= \\
\sqrt{2} \int_{-1}^{1} K(s) d B_{y,(s+1) / 2}^{*} & \equiv Q
\end{aligned}
$$

This leads to

$$
T^{-2} h \sum_{j=1}^{T} S_{j}^{2}=T^{-1} \sum_{j=1}^{T}\left(T^{-1 / 2} h^{1 / 2} S_{j}\right)^{2} \Longrightarrow Q^{2}
$$

proving the result.

\section{Monte Carlo Exercise}

In this section, we study the finite sample properties of our time-varying extension to the KPSS test. We simulate data using the model in Equation (2) as the data generating process where $\beta_{t}$ is a bounded random walk

$$
\beta_{t}=\sum_{i=1}^{t} v_{t} / \sqrt{t}, v_{t} \sim \mathcal{N}(0,1) .
$$

Based on these simulated samples, Table 1 compares the rejection probabilities of our KPSS test at $95 \%$ under the null of cointegration $\left(u_{t} \sim I(0)\right)$ and Table 2 presents the rejection probabilities under the alternative of no cointegration $\left(u_{t} \sim I(1)\right)$ for a range of sample sizes and bandwidths. We find that the test's size is close to the nominal $5 \%$ for different bandwidths even for small sample sizes. Table 2 also presents the empirical size of the standard time invariant KPSS test, and it is clear that when the true DGP features TV parameters, ignoring the time variation will result in extensively oversized tests, e.g. for sample sizes of over 600 , the test will always reject the null of cointegration, even though a timevarying cointegrating relationship exists. For the power comparison under the alternative, we examine 
two DGPs: one with parameter time variation as before $\left(\beta_{t}\right)$, and another with fixed parameters $(\beta=1)$. In each case considered, the power is increasing in the sample size, and relatively smaller bandwidths deliver better power. From Table 2 it is clear that we get good power with our TV KPSS test, even when the true DGP does not feature parameter time variation.

\begin{tabular}{|c|c|c|c|c|}
\hline \multirow{2}{*}{$\begin{array}{c}\text { Bandwidth, } T^{\alpha} \\
\alpha\end{array}$} & \multicolumn{4}{|c|}{$\begin{array}{l}\text { Rejection probabilities } \\
\text { under the null, kernel }\end{array}$} \\
\hline & $\mathrm{T}=200$ & $\mathrm{~T}=400$ & $\mathrm{~T}=600$ & $\mathrm{~T}=800$ \\
\hline 0.20 & 0.047 & 0.049 & 0.064 & 0.048 \\
\hline 0.25 & 0.054 & 0.050 & 0.045 & 0.037 \\
\hline 0.30 & 0.065 & 0.058 & 0.061 & 0.057 \\
\hline 0.35 & 0.042 & 0.052 & 0.060 & 0.053 \\
\hline 0.40 & 0.054 & 0.060 & 0.048 & 0.043 \\
\hline 0.45 & 0.055 & 0.047 & 0.053 & 0.055 \\
\hline 0.50 & 0.058 & 0.057 & 0.045 & 0.062 \\
\hline 0.55 & 0.061 & 0.052 & 0.055 & 0.061 \\
\hline 0.60 & 0.056 & 0.047 & 0.043 & 0.059 \\
\hline 0.65 & 0.066 & 0.039 & 0.038 & 0.041 \\
\hline 0.70 & 0.042 & 0.037 & 0.042 & 0.049 \\
\hline 0.75 & 0.061 & 0.058 & 0.042 & 0.052 \\
\hline 0.80 & 0.040 & 0.046 & 0.054 & 0.052 \\
\hline 0.85 & 0.053 & 0.061 & 0.048 & 0.041 \\
\hline \multirow[t]{3}{*}{0.90} & 0.043 & 0.044 & 0.039 & 0.040 \\
\hline & \multicolumn{4}{|c|}{$\begin{array}{l}\text { Rejection probabilities under } \\
\text { the null, time invariant KPSS }\end{array}$} \\
\hline & 0.948 & 0.980 & 1.000 & 1.000 \\
\hline
\end{tabular}

Table 1: Size of the KPSS test and its TVP extension in the presence of parameter time variation

\section{Application to UK Great Ratios}

Kaldor (1961) put forward a set of 'stylised facts' that were considered as universal characteristics of long-run growth. Among these were that capital and labour shares and the capital output ratio were 


\begin{tabular}{c|cccc|cccc}
\hline \multirow{2}{*}{ Bandwidth, $T^{\alpha}$} & \multicolumn{3}{|c|}{$\begin{array}{c}\text { Rejection probabilities } \\
\text { under the alternative } b_{t}\end{array}$} & \multicolumn{3}{c}{$\begin{array}{c}\text { Rejection probabilities } \\
\text { under the alternative } b=1\end{array}$} \\
\cline { 2 - 9 }$\alpha$ & $\mathrm{T}=200$ & $\mathrm{~T}=400$ & $\mathrm{~T}=600$ & $\mathrm{~T}=800$ & $\mathrm{~T}=200$ & $\mathrm{~T}=400$ & $\mathrm{~T}=600$ & $\mathrm{~T}=800$ \\
\hline \hline 0.20 & 0.605 & 0.740 & 0.828 & 0.891 & 0.630 & 0.737 & 0.861 & 0.893 \\
0.25 & 0.663 & 0.732 & 0.830 & 0.890 & 0.701 & 0.726 & 0.822 & 0.919 \\
0.30 & 0.631 & 0.770 & 0.804 & 0.874 & 0.653 & 0.791 & 0.811 & 0.904 \\
0.35 & 0.597 & 0.762 & 0.819 & 0.861 & 0.638 & 0.785 & 0.812 & 0.878 \\
0.40 & 0.608 & 0.711 & 0.752 & 0.824 & 0.628 & 0.728 & 0.807 & 0.891 \\
0.45 & 0.577 & 0.672 & 0.733 & 0.768 & 0.651 & 0.663 & 0.754 & 0.775 \\
0.50 & 0.548 & 0.618 & 0.667 & 0.756 & 0.585 & 0.643 & 0.675 & 0.746 \\
0.55 & 0.506 & 0.587 & 0.645 & 0.713 & 0.522 & 0.616 & 0.670 & 0.779 \\
0.60 & 0.495 & 0.549 & 0.593 & 0.653 & 0.549 & 0.580 & 0.573 & 0.664 \\
0.65 & 0.466 & 0.498 & 0.545 & 0.565 & 0.463 & 0.482 & 0.538 & 0.562 \\
0.70 & 0.392 & 0.391 & 0.491 & 0.509 & 0.359 & 0.464 & 0.524 & 0.551 \\
0.75 & 0.352 & 0.393 & 0.395 & 0.442 & 0.387 & 0.389 & 0.418 & 0.449 \\
0.80 & 0.303 & 0.342 & 0.364 & 0.365 & 0.325 & 0.372 & 0.380 & 0.391 \\
0.85 & 0.272 & 0.276 & 0.350 & 0.331 & 0.213 & 0.282 & 0.324 & 0.365 \\
0.90 & 0.273 & 0.289 & 0.292 & 0.313 & 0.288 & 0.309 & 0.329 & 0.380 \\
\hline
\end{tabular}

Table 2: Power of the TVP KPSS extension in the presence of constant and TV parameter

stable over time. In the same year Klein and Kosobud (1961) used the phrase 'great ratios' in the title of their paper to indicate stable and constant relationships between key variables that are to be expected in balanced growth models. However, not all models exhibit this, including: endogenous growth models (examined empirically by Jones (1995), rejecting varying steady state growth); models with multiple equilbria (eg Farmer et al. (2009)); and hysteresis in labour markets which was a popular feature of models in the 1980s (a modern formulation is to be found in Galí (2015)). Even when the Klein and Kosobud (1961) conditions are in place, deep parameters might change over time. Nevertheless, constant parameter balanced growth remains the default assumption in the majority of macroeconomic models.

It is natural to put to a statistical test the balanced growth idea, by testing the great ratios for stationarity. Papers which do this include King et al. (1991), Serletis (1994), Harvey et al. (2003), Clements (2016) and Franchi and Jusélius (2007). The overall evidence for constant parameter cointegrating vectors is weak. Following Whelan (2003), Attfield and Temple (2010) focussed on nominal shares as we do and allowed for discrete location (mean) shifts. The evidence of cointegration is then stronger. But the existence of a 

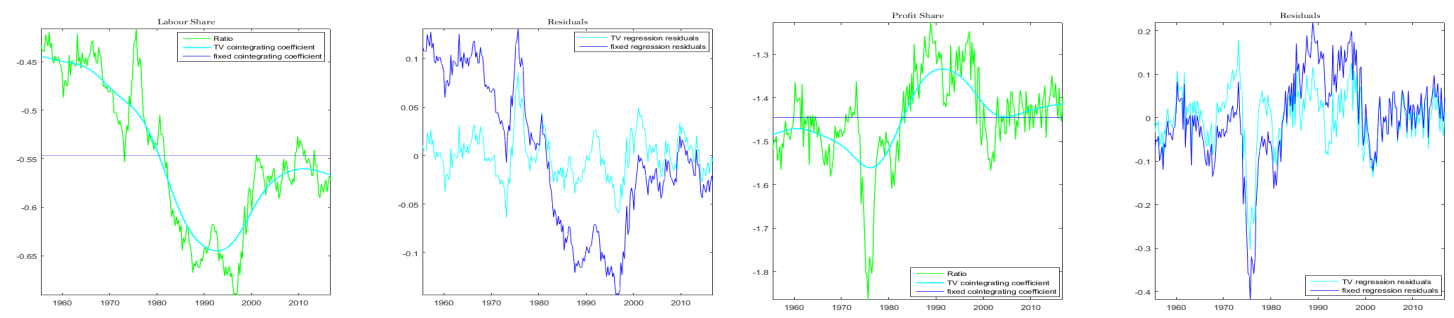

Figure 1: Labour share

Figure 2: Profit share

small number of discrete location shifts is not compelling, and this motivates our approach. which allows for continuous parameter changes.

We consider models of the form

$$
y_{t}-x_{t}=\alpha_{t}+\varepsilon_{t}
$$

where $y_{t}$ and $x_{t}$ indicate the $\log$ of the variables $Y_{t}$ and $X_{t}$ respectively. We use a bandwidth of $T^{0.5}$, motivated by Giraitis et al. (2014) who find that is optimal in terms of estimation MSE 4 The cointegrating vector associated with the set $\left\{y_{t}, x_{t}\right\}$ is restricted to be $\{1,-1\}$ so the cointegrating relationship defines the $\log$ great ratio $y_{t}-x_{t}-\alpha_{t}$. In the fixed coefficient case $\alpha_{t}=\alpha \forall t$. Figures 1 to 8 show the unconditional mean (the fixed cointegrating coefficient, $\alpha$ ), the actual data for the great ratios or shares (ratio) and the time-varying mean ( $T V$ cointegrating coefficient, $\left.\alpha_{t}\right)$ in the left-hand panels. In the right-hand panels, the fitted cointegrating residuals are illustrated. In most cases the raw ratios (fixed mean) do not look stationary, with the possible exception of the profit share. By contrast, the TV coefficient residuals are more plausible candidates for stationarity. It is hard to give a deep economic interpretation of movements in these long run relationships as we are not estimating a structural model, but in Kapetanios et al. (2019) the broad changes in the ratios that we are finding here are interpretable in terms of shifting structural parameters in a benchmark equilibrium model.

Table 3 reports the values for the KPSS test statistif $5^{5}$ for cointegration among the nomina ${ }^{6}$ ratios. Rejections of the null (cointegration) at the $5 \%$ level are indicated in the tables with '**'. For the fixed parameters, the null of cointegration is rejected in six out of eight cases 7 By contrast, where TV is allowed in no case is the null rejected.

\footnotetext{
${ }^{4}$ An alternative would be to use some form of cross validation, for example by minimising the one-step ahead forecasts in or out of sample.

${ }^{5}$ Using the standard Newey-West estimate of the long-run variance.

${ }^{6}$ In Kapetanios et al. (2019), we also consider real series.

${ }^{7}$ It cannot be rejected at $5 \%$ for the two trade ratios. This may be because the null allows the possibility of a deterministic trend in the cointegrating space.
} 

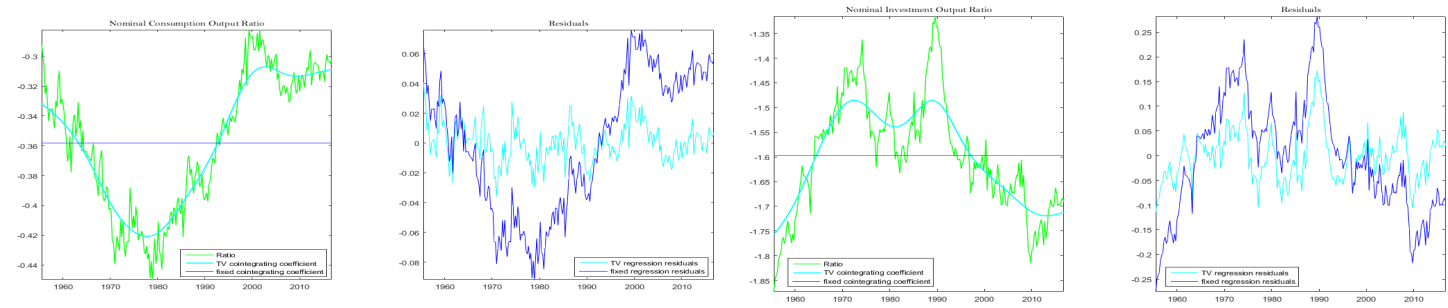

Figure 3: Consumption-output ratio (nominal)

Figure 4: Investment-output ratio (nominal)
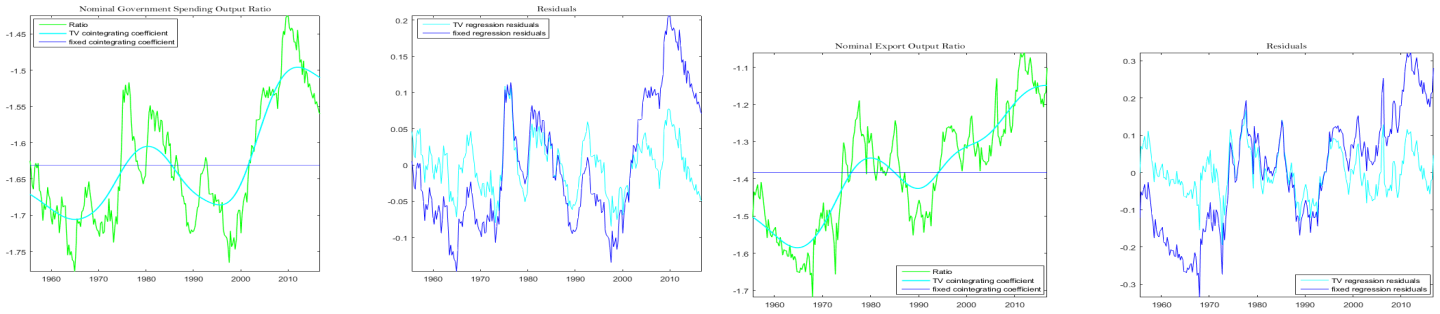

Figure 5: Government consumption-output ratio (nominal)

Figure 6: Export-output ratio (nominal)
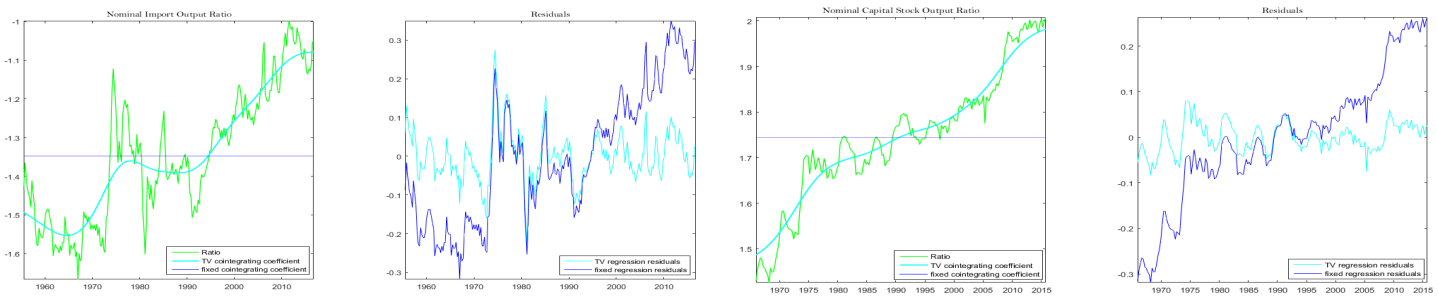

Figure 7: Import-output ratio (nominal)

Figure 8: Capital-output ratio (nominal: stock) 


\begin{tabular}{l|c|c}
\hline \multicolumn{1}{c|}{ Ratio } & TV KPSSS & Fixed KPSS \\
\hline \hline $\mathrm{C} / \mathrm{Y}$ & 0.13 & $0.44^{* *}$ \\
$\mathrm{I} / \mathrm{Y}$ & 0.07 & $0.39^{* *}$ \\
$\mathrm{G} / \mathrm{Y}$ & 0.05 & $0.19^{* *}$ \\
$\mathrm{X} / \mathrm{Y}$ & 0.05 & 0.11 \\
$\mathrm{M} / \mathrm{Y}$ & 0.04 & 0.15 \\
$\mathrm{~K} / \mathrm{Y}$ & 0.09 & $0.17^{* *}$ \\
Labour share & 0.06 & $0.42^{* *}$ \\
Profit share & 0.04 & $0.15^{* *}$ \\
\hline
\end{tabular}

** indicates rejection of the null of cointegration at $5 \%$.

$C=$ consumption, $Y=$ output,$I=$ investment,$G=$ government consumption, $X=$ exports, $M=$ imports, $K=$ capital stock

Table 3: KPSS test statistics from time varying (TV) and fixed parameter cointegration for nominal Great Ratios

\section{Conclusions}

We present a method for estimating and testing for the existence of time varying cointegrating relationships. We apply our procedure to the UK 'great ratios' which in balanced growth models are expected to be stationary. We find little evidence for such stationarity where parameters are estimated as constant, but strong evidence when we explicitly allow for time variation. This implies that practical macroeconometric models could be built allowing for this variation, which may deliver better in-sample fit and out-of-sample forecasting performance. One implication is that DSGE models built on the assumption of constant deep parameters may be unable to correctly represent the data particularly when long time span is considered, a conclusion also drawn by Franchi and Jusélius (2007). 


\section{References}

Attfield, C. And J. R. Temple (2010): "Balanced growth and the great ratios: New evidence for the US and UK," Journal of Macroeconomics, 32, 937-956.

Bierens, H. ANd L. Martins (2010): "Time-varying cointegration," Econometric Theory, 26, 14531490.

Clements, M. (2016): "Long-run restrictions and survey forecasts of output, consumption and investment," International Journal of Forecasting, 32, 614-628.

Dahlhaus, R. (2000): "A likelihood approximation for locally stationary processes," The Annals of Statistics, 28, 1762-1794.

Dahlhaus, R. And W. Polonik (2006): "Nonparametric quasi maximum likelihood estimation for Gaussian locally stationary processes," The Annals of Statistics, 34, 2790-2824.

Farmer, R. E. A., D. F. Waggoner, and T. Zha (2009): "Indeterminacy in a forward-looking regime switching model," International Journal of Economic Theory, 5, 69-84.

Franchi, M. AND K. JusÉLius (2007): "Taking a DSGE Model to the Data Meaningfully," Economics - The Open-Access, Open-Assessment E-Journal, 1, 1-38.

Galí, J. (2015): "Hysteresis and the European Unemployment Problem Revisited," Working Papers 837, Barcelona Graduate School of Economics.

Giraitis, L., G. Kapetanios, and T. Yates (2014): "Inference on stochastic time-varying coefficient models," Journal of Econometrics, 179, 46-65.

- (2018): "Inference on multivariate heteroscedastic stochastic time varying coefficient models," Journal of Time Series Analysis, 39, 129-149.

Harvey, D. I., S. J. Leybourne, And P. Newbold (2003): "How great are the great ratios?" Applied Economics, 35, 163-177.

Jones, C. (1995): "Time Series Tests of Endogenous Growth Models," The Quarterly Journal of Economics, 110, 495-525.

KALDOR, N. (1961): "Capital accumulation and economic growth," in The Theory of Capital, ed. by F. A. Lutz and D. C. Hague, St Martins Press.

Kapetanios, G., S. Millard, K. Petrova, and S. Price (2019): "Time-varying cointegration and the UK great ratios," Bank of England Working Papers 789, Bank of England. 
King, R. G., C. I. Plosser, J. H. Stock, And M. W. Watson (1991): "Stochastic trends and economic fluctuations," American Economic Review, 81, 819-40.

Klein, L. R. And R. F. Kosobud (1961): "Some Econometrics of Growth: Great Ratios of Economics," The Quarterly Journal of Economics, 75, 173-98.

PARK, J. AND S. B. HAhn (1999): "COINTEGRATING REGRESSIONS WITH TIME VARYING COEFFICIENTS," Econometric Theory, 15, 664-703.

Phillips, P., D. Li, and J. GaO (2017): "Estimating smooth structural change in cointegration models," Journal of Econometrics, 196, 180-195.

Serletis, A. (1994): "Testing the long-run implications of the neoclassical growth model for Canada," Journal of Macroeconomics, 16, 329 - 346.

Shin, Y. (1994): "A Residual-Based Test of the Null of Cointegration against the Alternative of No Cointegration," Econometric Theory, 10, 91-115.

Whelan, K. (2003): “A Two-Sector Approach to Modeling U.S. NIPA Data," Journal of Money, Credit and Banking, 35, 627-656. 